\title{
On the replacement of steel by NITINOL as coupling agent in automobile shaft
}

\author{
Lokanath Barik $^{1} \cdot$ Saswat Samal ${ }^{2} \cdot$ Ajit Behera $^{2} \cdot$ Dipen Kumar Rajak ${ }^{3} \cdot$ Catalin I. Pruncu $^{4}$ (D)
}

Received: 2 May 2021 / Revised: 20 July 2021 / Accepted: 21 July 2021 / Published online: 2 August 2021

(C) Crown 2021

\begin{abstract}
Automobile couplings generally fail due to excessive misalignment in shafts and torque overload which ultimately generates vibration in the assembly. These vibrations weaken the coupling structure and ultimately get transmitted to the shaft leading to fatigue failure. Additionally, the complexity in the design of standard coupling is related to lower durability. In this system, when the radial space is larger, it triggers a bulkier transmission. Shape memory alloy such as NITINOL is a special class of smart material that possesses superelasticity which means it can retain deformation of about $8 \%$. This material has a high degree of strength, greater elastic and shear modulus than existing coupling materials, such as steel, and has unique vibration damping features. Coupling made of NITINOL is simple in design and requires lesser space with minimal maintenance. They provide higher durability and are much reliable in operation over a wide range of temperatures. This paper aims to review the NITINOL material used in coupling technology industries and the parameters governing its shape memory effect. The knowledge gathered from this work enables to further extend the technological contribution to NiTi coupling at large-scale production in the automobile sector with direct effect on longer life for the transmission system.
\end{abstract}

Keywords Coupling $\cdot$ Automobile $\cdot$ NITINOL $\cdot$ Shape memory effect $\cdot$ Coupling durability

\section{Introduction}

All automobiles are made up of several machine elements with the role of transmitting the power. Once the engine generates the power, it is transmitted to the wheels through the shaft. If the transmission distance is too long and if any

Ajit Behera

ajit.behera88@gmail.com

$\triangle$ Dipen Kumar Rajak

diepn.pukar@gmail.com

$\triangle$ Catalin I. Pruncu

Catalin.pruncu@strath.ac.uk

1 Department of Mechanical Engineering, National Institute of Technology, Rourkela 769008, India

2 Department of Metallurgical and Materials Engineering, National Institute of Technology, Rourkela 769008, India

3 Department of Mechanical Engineering, Sandip Institute of Technology and Resaerch Centre, Nashik 422213, India

4 Design, Manufacturing and Engineering Management, University of Strathclyde, Glasgow G1 1XJ, Scotland, UK non-coaxial shafts are used for the power transmission, then vibrations will be induced due to shock and overload, which give rise to premature failure of these shafts. The coupling is used from the driver shaft to the driven shaft for effective power transmission to eliminate these issues. Coupling is a mechanical device that connects two shafts at their ends for power transmission. They are generally used in coaxial shafts, angular misaligned shafts, lateral misaligned shafts, axial misaligned shafts. Couplings are broadly divided into two categories: (1) rigid coupling (Muff, Split Muff, and Flange) for collinear or coaxial shafts and (2) flexible couplings (Bush pin type flange, Oldham, Universal) for noncollinear or non-coaxial shafts (Bhandari 2001). Certain factors need to be considered while designing a coupling for connecting shafts considering certain influencing parameters that govern its dynamics and applicability. Table 1 represents those factors and the parameters influencing them during the selection of the coupling agent.

Couplings are generally designed considering a certain torque limit, and it is advisable to operate under that limit 
Table 1 Factors considered during the shaft coupling selection

\begin{tabular}{ll}
\hline Factors & Respective influencing parameters \\
\hline Material factors & Strength \\
& Weight \\
& Bore diameter of shaft \\
& Moment of Inertia \\
& Axial and radial forces \\
& Torsional moment \\
& Bending moment \\
& Torque rating \\
& Torsional stiffness and torsional rigidity \\
& Torsionally flexible \\
& Backlash \\
& Space requirement \\
& Misalignment capacity \\
& Balancing \\
& Engaging \\
& Disengaging \\
Safety flange & Service factor \\
Operational factors & Operating time \\
Start per hour \\
Electricity supply frequency \\
Maintenance \\
Temperature \\
Corrosive wear \\
Abrasive wear \\
Vertical and horizontal shafts \\
Fits \\
Alignment \\
Internal standards \\
Cost \\
Coupling safeguards \\
\\
\end{tabular}

only. Sometimes heavy torque fluctuations are seen in the automobile from an engine firing cylinder or reciprocating pumps, which causes significant damage to couplings. High magnitude torque fluctuations cause severe vibration from unbalancing forces unless the load is so monstrous that sudden failure is observed at a different parts of coupling thereby leading to failing catastrophically (Khan 2019). Misalignment between shafts, when connected through rigid or stiff coupling at even the slightest, creates an unbalanced force component which is converted into external excitation. These vibrations weaken the structure causing the shaft assembly to fail prematurely. In general, vibrations of the shafts are minimized so that they will not achieve their natural frequency. Otherwise, resonance comes into play, and high amplitude excitations are generated. It also results in the loosening of the shaft coupling system which hinders smooth rotation and power transmission. The consequences also include worn-off components and slow gear speed, hence vibration mitigation is much essential for parametric design (Stephen et al. 2013). The problem could be solved by using NiTi SMA coupling. The inherent behavior of this superelastic coupler gives advanced vibration damping capacity under cyclic torsional loading results in strong fatigue resistance (Wolfgang et al. 2006). Enhancement of fatigue limit allows a high absorption capacity of torsional oscillation and provides the operator with a broader safe zone (Raphael and Thiago 2021). Besides this, the coupling can adjust the misalignment in shafts and provides a long-lasting tightened joint that is pre-stressed by residual compressive forces. To counteract misalignment, a flexible coupling could be used. But they fail due to torque overload and its parts gradually wear off as in the case of rubber used in couplings. Flexible couplings such as leaf spring coupling in heavy vehicles can cause velocity loss between shafts. The loss in velocity affects the orientation and position of the shafts due to which vibrations are induced which wears off bearings/gears. In general, failure in shaft and coupling assembly is observed mainly due to misalignment, torque overload, loosening, velocity loss, and backlash. Out of these failure conditions, misalignment in shafts and torque overload are the prime causes of failure during operation (Bhandari 2001; Khan 2019; Stephen et al. 2013). The contributions to different failure modes of automobile shaft is shown in Fig. 1.

To prevent the harmful effect from spreading to other parts of rotating machinery, periodic maintenance is required which is again a costly affair. Vibration-based condition monitoring is generally deployed for periodic

\section{Failure Modes in Coupling}

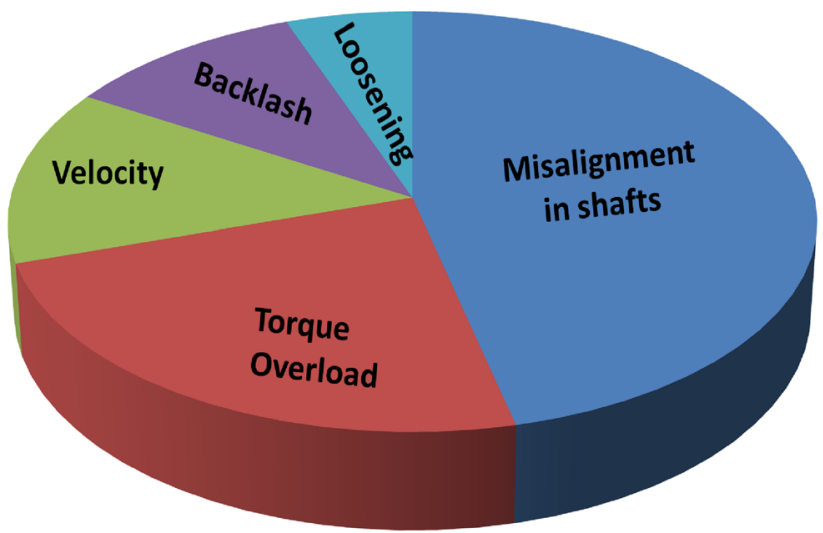

Fig. 1 Percentage of failure for different modes in automobile shaft 
maintenance which includes equipment such as accelerometers, data acquisition, and signal processing systems. (Deepam and Pabla 2015). On the other hand, damaged coupling leads to standstill operation of the rotating system. The installation of a new coupling also requires a skilled operator and an adequate time. In contrast, SMA coupling is much promising and can be installed within (30-60) sec as used during pipe joining applications in aircrafts. SMA coupling also requires very less maintenance (Pamela 1987).

In the present scenario, materials used for rigid coupling and hubs of flexible coupling are available in gray cast iron, aluminum, stainless steel, alloy steel, brass, and advanced thermoplastics. In general, aluminum is the best default choice for metallic coupling because of its economical cost. Also, because it is able to sustain well the coating process which improves the corrosion resistance and wear characteristics (Kai and Sirong 2020). Alloy steel and brass being cheaper are also used as coupling materials for low-pressure fuel lines. However, stainless steel provides excellent corrosion resistance and high strength over a wide range of temperatures and its property is attributed to fine grain structure hence used in universal coupling (Wagner and Cooney 1979). For flexible couplings, materials such as nylon and high-temperature molded rubber are used as per their convenience and level of misalignment between shafts. NITINOL can withstand more to wear than steel alloys used in conventional coupling due to its harder surface characteristics. It can also withstand extreme vibrations and not loosen due to its elastic preloaded condition without using adhesives to hold the assembled components and/or the connector itself together (Manoj et al. 2020). In most practical applications, NiTi Smart materials are replacing the conventional ones due to their intrinsic and extrinsic healing abilities and better anticorrosive properties than steel (Cuia and B. 2020). Besides this, steel has a high coefficient of thermal expansion (at temperature around $300{ }^{\circ} \mathrm{C}$ ), steel loses its properties. Further, beyond $400{ }^{\circ} \mathrm{C}$, their loss in strength is drastic, which can be detrimental to the overall component, whereas NiTi alloy possesses better thermal stability with microstructural enhancement and can resist temperature up to $600{ }^{\circ} \mathrm{C}$ (Mehmet et al. 2017). Joints in coupling made of steel are brazed which provides weaker strength and gives different properties, when heated to a higher temperature, whereas NITINOL coupling is joined by shape memory effect without any special tools or manufacturing process. Furthermore, SMA coupling can be used for dissimilar materials which cannot be welded. NiTIiNOL $(6450 \mathrm{~kg} /$ $\left.\mathrm{m}^{3}\right)$ is comparatively less dense than steel $\left(8050 \mathrm{~kg} / \mathrm{m}^{3}\right)$ making the system lighter and compact. Along with it, the installation is quite convenient and takes around $30 \mathrm{~s}$ to complete the joint and sealing of tubes as seen in pipe joining application in the Chinese Y12F aircraft hydraulic system (Du and Xu 2015). Juergen et al. (Juergen 1983) conducted an experiment taking stainless steel and NiTi wire of various cross sections and performed stepwise twisting using a torque meter. He found that the elastic range of NITINOL wire with respect to permanent angulations was approximately double that of stainless steel. In a wire of the nominal dimensions $(0.017 \times 0.025)$, it was observed that to produce a $20^{\circ}$ progressive torque having a magnitude of $20 \times 10^{-3} \mathrm{~N} . \mathrm{m}$, the stainless steel wire was twisted through $150^{\circ}$, whereas NITINOL wire was turned through $300^{\circ}$. This indicated that the stiffness of stainless steel wire was higher, and hence, it resists angular deformation nearly twice that of the NITINOL wire of the same dimension. Upon changing the cross section, the stiffness changes which thereby changes the torquability of these materials but it was observed that the trend remains the same. When the experiments were conducted for a wire of circular cross section of NITINOL provided at 1, 3, and $25 \mathrm{~mm}$ nominal diameter, the optimum results were observed in the case of wire of $3 \mathrm{~mm}$ diameter where it was able to sustain a permanent torque of around $41 \times 10^{-3}$ N.m and a torque angulation up to $135^{\circ}$ before failure. The excellent torquability of NITINOL compared to steel and stable operation over a wider range of temperature is attributed to its low coefficient of thermal expansion at the austenitic phase. Being superelastic in nature, the Young's modulus of NITINOL is low but it can withstand more tensile load until failure due to its higher ultimate tensile strength. The ultimate strength of a standard SMA coupling was found to be around twice that of traditional interference fit coupling upon performing load testing. SMA coupling was able to bear a tensile load over $4000 \mathrm{~N}$ when designed to be as small as one cubic centimeter (Crane et al. 2014). These couplings despite being very simpler in design and mechanism offers amazing results. Table 2 gives a comparative study of the mechanical properties of NITINOL and steel.

As per the previous literature, there is limited information related to smart automobile coupling. Therefore, this paper focused on reviewing the NITINOL coupling in various automobile parts. NITINOL is a special class of smart material that possesses superelasticity properties to recover its shape at its working temperature. In addition, this material provides greater elastic and shear modulus as compared to steel and vibration damping features along with the shape recovery phenomenon. All the major influencing parameters associated with the coupling agent have been discussed in this work. 
Table 2 Comparison between NITINOL and stainless steel

\begin{tabular}{lll}
\hline Properties & NITINOL & Stainless steel \\
\hline Recovered elongation & $8 \%$ & $0.8 \%$ \\
Youngs modulus & Martensite-25 GPa & $193 \mathrm{GPa}$ \\
& Austenite-75 GPa & \\
Torque ability & Excellent & Poor \\
Density & $6.45 \mathrm{~g} / \mathrm{cm}^{3}$ & $8.03 \mathrm{~g} / \mathrm{cm}^{3}$ \\
UTS & Approx. $1240 \mathrm{MPa}$ & Approx. $760 \mathrm{MPa}$ \\
Thermal expansion coefficient & Martensite- $6.6 \times 10^{-6} \mathrm{~cm} / \mathrm{cm} /{ }^{\circ} \mathrm{C}$ & $17.3 \times 10-6 \mathrm{~cm} / \mathrm{cm} /{ }^{\circ} \mathrm{C}$ \\
& Austenite- $11.0 \times 10^{-6} \mathrm{~cm} / \mathrm{cm} /{ }^{\circ} \mathrm{C}$ & \\
\hline
\end{tabular}

\section{Historical background of NiTi coupling}

The year 1962 paved the way for SMA in the form of NITINOL $\left(\mathrm{Ni}_{50} \mathrm{Ti}_{50}\right)$ developed by the Naval Ordinance Laboratory. NiTi alloy was found to possess shape memory properties upon stress-induced heating. After its discovery, the application of NITINOL spread into many diverse sectors where its properties were exploited for industrial application as well. In 1969, NITINOL was shaped as a coupler used for joining pipes. The initiative was taken by Raychem's Corporation who had wide expertise in heatshrinkable plastics. The coupler was named Cryofit or Shrinko-fit pipe coupler which was used to join hydraulic fluid lines in the F-14 jet fighter built by Grumman Aerospace Corporation (Liu et al. 2006). Further, it was used to join titanium tubes in the U.S. Navy. The product was a line of 3000 psi hydraulic coupling. It was commercialized, and over 3 million couplings were put to service in the year 1971 (Tabesh et al. 2017). After a decade, SMA coupling became widely popular, and in 1974, it was used as connectors in the navigation system of the Trident missile. These connectors were primarily very reliable under the high shock and vibration environment of the missile system. In 1975, the British Royal Navy implemented 6000psi coupling for its Trafalgar class Nuclear submarines. Later in 1976, U.S. Navy used it on its surface ships. These couplings used NiTi-Fe alloy as the coupling material. During the beginning of 1980, NiTi alloy, such as NiTiNb, connectors were used in the FMC Bradley Fighting vehicle, piezoelectric accelerometers, tube fittings used in naval gage lines, and other Military and Aerospace applications (George and Isaac 1997). Beginning in 1989, NiTi-Fe rings were used to clamp polyurethane hose to the fittings in sonar towered arrays. During 1990, NiTiNb rings were used for metal wiring conduits on domestic civilian aircraft. Influenced by its benefits, Raychem launched a standardized line of SMA fastener rings in 1992 under the name UniLok ${ }^{\circledR}$. By 1993, the rings find uses in a broad range of new applications, including clamping a bundle of optical components in a particle counter, sealing a cover to a pressure sensor, joining aerospace valve components, retaining a 10-inch diameter nuclear seal, and providing a stop on a rocket motor shuttle valve. SMA tube in sealing connection of hydraulic system on Y12F airplane was tested on three planes with $400 \mathrm{~h}$ of flight, and no case of leakage was found by the Chinese Air-force ( $\mathrm{Du}$ and $\mathrm{Xu}$ 2015). SMAs are now used as actuators, controllers, vibration isolators, sensors, dampers, and structural connectors. SMA of NiTi is commonly implemented in oil and gas industries for piping networks (Patil and Song 2016). SMA couplers are recently used in offshore hydraulic control equipment as a tubing solution replacing welded joints (Karakoc et al. 2021). Recently, it has been reported to be used in nuclear reactors (high energy particle accelerators) as beam pipe connectors providing temperatureinduced clamping and unclamping with remote activation (Niccolia et al. 2017). This NiTi coupling is now known as smart coupling.

\section{Smart effect in coupling}

SMA is a functional material with a high energy density that can provide maximum work output per unit volume. NiTi alloy is produced using a process chain that starts with the fabrication of predetermined composition, primary shaping process, pretreatment, and training. It can be fabricated by both conventional and non-conventional methods such as casting, powder metallurgy process, selective laser melting, selective laser sintering, and electron beam melting (Sharma et al. 2015). At high temperatures, NITINOL exists in a simple cubic BCC structure referred to as austenite which on cooling gets converted into a more complicated monoclinic crystal structure spontaneously, known as martensite. This crystal structure has the ability to undergo limited deformation by atomic shear without breaking the bonds. This phenomenon is characterized by twinning and de-twinning which is the collective motion of atoms on distances smaller than lattice parameters (Nnamchi et al. 2019). This means if the NITINOL wire is 
bend, the internal structure remains intact. Upon heating, the SMA recognizes its initial shape and the de-twinned martensite structure is converted to austenite, its original dimension. To account for the thermal motion, the atoms slip back to their original lattice configuration from the austenite phase retaining their original shape. In NITINOL, an overall strain approaching $8 \%$ can be attributed to martensite shear conveying superelasticity or pseudo-elasticity behavior (Otsuka and Ren 2005). This property is often called the two-way property of shape memory alloy. In non-memory metals, the atoms in the crystal lattice are held rigidly. They can compensate for deformation under the elastic limit only. Beyond the yield point, plastic deformation takes place where atoms slip to the nearest position out of their unit cell and bond weakens. This phenomenon is irreversible, hence a permanent plastic deformation is observed in the form of non-recoverable strain energy as shown in Fig. 2a. In NITINOL, however, atoms move along with their lattice position instead of leaving their unit cell which gets restored upon heating above austenite transformation temperature as shown in Fig. 2b (Naresh et al. 2016). All the phase transformation in NiTi smart system is known as Military transformation, which is the responsible factor for recovery.

\section{External coupling concept}

Tabesh et al. (2012) fabricated a NITINOL alloy coupler at room temperature originally in the austenite phase to the required coupling dimensions. The coupling size (D1) was made smaller with respect to the shaft or pipe diameter (D2), as shown in Fig. 3a. To produce the desired coupling effect, the coupler was placed in a liquid nitrogen bath at $-120{ }^{\circ} \mathrm{C}$ where the austenite grains are converted to elastic martensite. There the coupler was radially expanded to a diameter of Dm slightly above the outer diameter of the shaft or pipe to be joined, as shown in Fig. 3b. This was accomplished by forcing an oversize tapered mandrel longitudinally through the coupler bore. When continually cooled in liquid nitrogen, the coupler remained stably expanded. Coupling two sections of hydraulic pipe or shaft were then accomplished by simply inserting the pipe or shaft ends into the expanded NITINOL coupler, and then the coupler was allowed to warm to its near original, or memory, diameter (D1) on heating. But the contraction was restricted to the outer diameter of the pipe, allowing it to have a diameter (Df). The rest of the restricted strain was converted into residual compressive stress, ensuring that all recovery strain was used as joining force. The procedure takes nearly half a minute for the coupler to touch the skin of the pipe, as shown in Fig. 3c. The radial contraction of the coupler, combined with the very high associated force, provided a continuously clamping and sealed joint (Tabesh et al. 2012).

If we consider a shaft having a nominal diameter of $100 \mathrm{~mm}$, under $3 \%$ tolerance, the outer diameter will be between 97 and $103 \mathrm{~mm}$. For an SMA coupling, the inner diameter must be enlarged to not less than $103 \mathrm{~mm}$ during in martensitic phase. Then, the SMA joint must be warmed or heated to achieve an inner diameter of not more than $97 \mathrm{~mm}$. Hence, for the SMA coupling, it is expected to provide a shape memory effect of six percent at a minimum. It is evident that the shape memory capacity must be twice that of the tolerance of the shaft. Since the circumference of the shaft is a function of its diameter, it is possible to predict SMA capacity with the diameter of the shaft (William 2010). In this regard, the tolerance of the shaft is a prime variable while selecting SMA coupling.
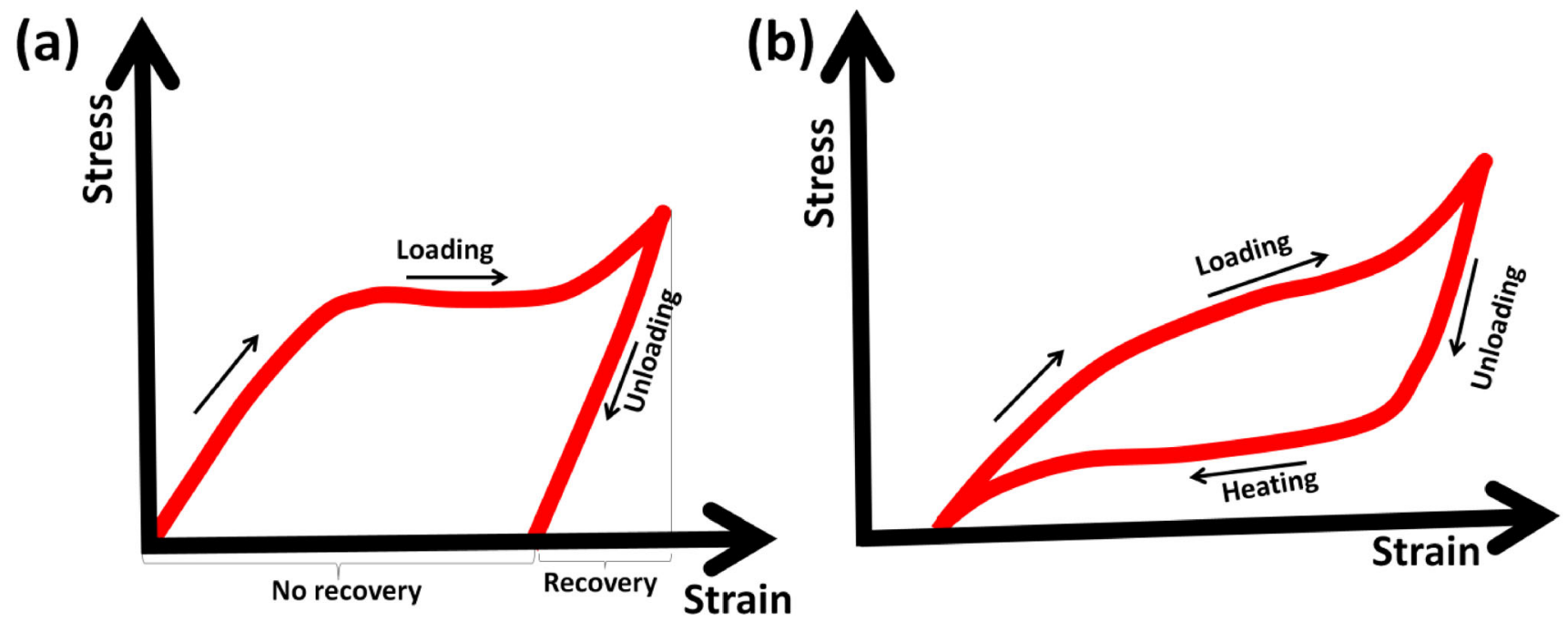

Fig. 2 Stress-strain behavior of a conventional material. b Pseudo-elasticity in SMA 

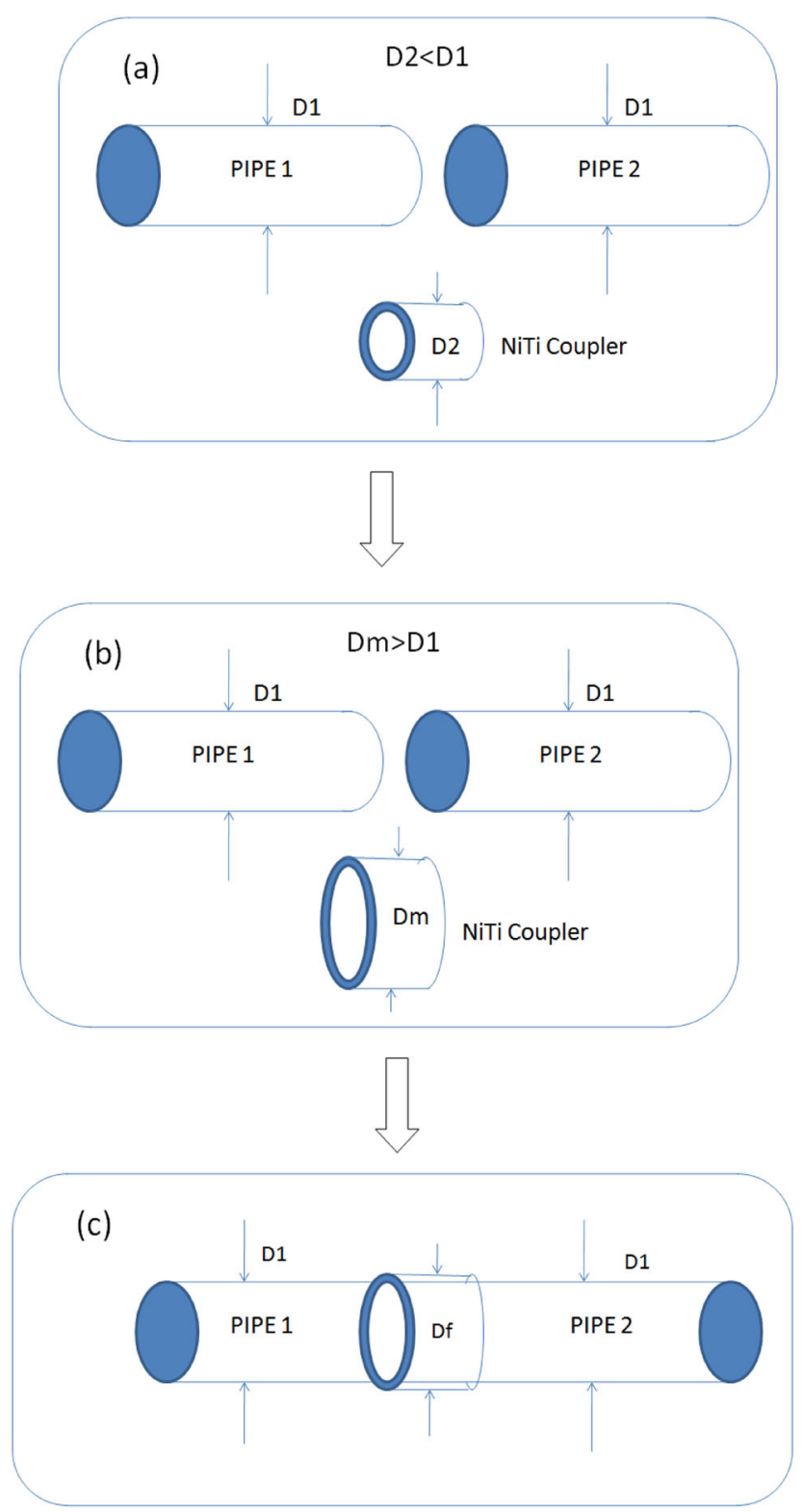

Fig. 3 Installation procedure of SMA coupling: a coupling agent in austenite phase, $\mathbf{b}$ expanded martensite phase in liquid $\mathrm{N}_{2}$, and $\mathbf{c}$ reconversion to austenite upon cooling forming tight joint

However, NiTi coupling provides $8 \%$ shape memory capacity which is quite sufficient enough to accommodate the tolerance limit as compared to the other materials alternatives (Wada and Liu 2005).

The contact stress increases linearly after heating it to austenite due to the difference in the coefficient of thermal expansion. Complete recovery is achieved by heating it beyond contact temperature. In NITINOL application, the transformation temperature is designed to be less than $-120{ }^{\circ} \mathrm{C}\left(-184^{\circ} \mathrm{F}\right)$, which is the required minimum operating temperature. Researchers have developed finite element analysis of the NiTi coupling considering actuation temperature and contact pressure and measured the same experimentally through a strain gauge installed at the inner surface of the coupling. The finite element analysis results showed an excellent match with experimental plots (Tabesh et al. 2018; Chen et al. 2020). The installation of SMA coupling is quite simple and convenient but there are certain procedures to be followed to obtain desired shape memory effect (Broyles and Jervis 1973). This technique was applied in F-14 fighter Aircraft and Petrochemical plants and was highly effective in producing leak-proof joints.

\section{External coupling concept}

Jee et al. (2006) investigated the joints between pipes. He proposed an internal coupling application that can compensate for different tolerance between pipes and alloy with low shape memory capacity. This technique used Fe30Mn-6Si SMA coupling which was inserted inside the pipes, both the coupling and the pipes were deformed simultaneously. Two pipes were taken having ID $25 \mathrm{~mm}$ and OD $28 \mathrm{~mm}$ and SMA coupling was taken of $25 \mathrm{~mm}$ OD and $22 \mathrm{~mm}$ ID. These both the pipes were uniformly contracted to a diameter of $27.2 \mathrm{~mm}$ OD. Then, the assembly was heated to $673 \mathrm{~K}$ where the coupling contracted on regaining its original shape and simultaneously the pipe expanded upon heating having a positive coefficient of thermal expansion. This anti-directional movement of pipe and coupler induced residual stresses because the strain was restricted and a strong joining force was obtained between the SMA and the steel pipes. Figure 4a represents the Fe-30Mn-6Si SMA coupling which was installed inside the pipes and both the pipe and the coupler were deformed upon heating above transformation temperature(austenite) unlike Fig. $4 \mathrm{~b}$ where the NiTi coupler was placed outside the pipes, in which the coupler gets contracted and no significant deformation in pipes was observed.

Most of the conventional method uses coupling agent in the interior of the joining of two pipes, whereas smart coupling system is used typically at the exterior position of the joining. Mori et al. (1997) investigated a similar coupling where he observed that pipe tolerance was eliminated during the process, there was no shape memory capacity loss due to tolerance. Accordingly, it is possible to apply alloys having a low shape memory capacity. Unlike NITINOL, where the coupling is subjected to extremely low temperature, the SMA could be deformed not only below but above reverse transformation temperature. However, it is worth noting that the deformed pipes undergo permanent dimension change when heated along with the coupling and this process cannot be applied for joining shafts. In addition to it, there is always a constant 

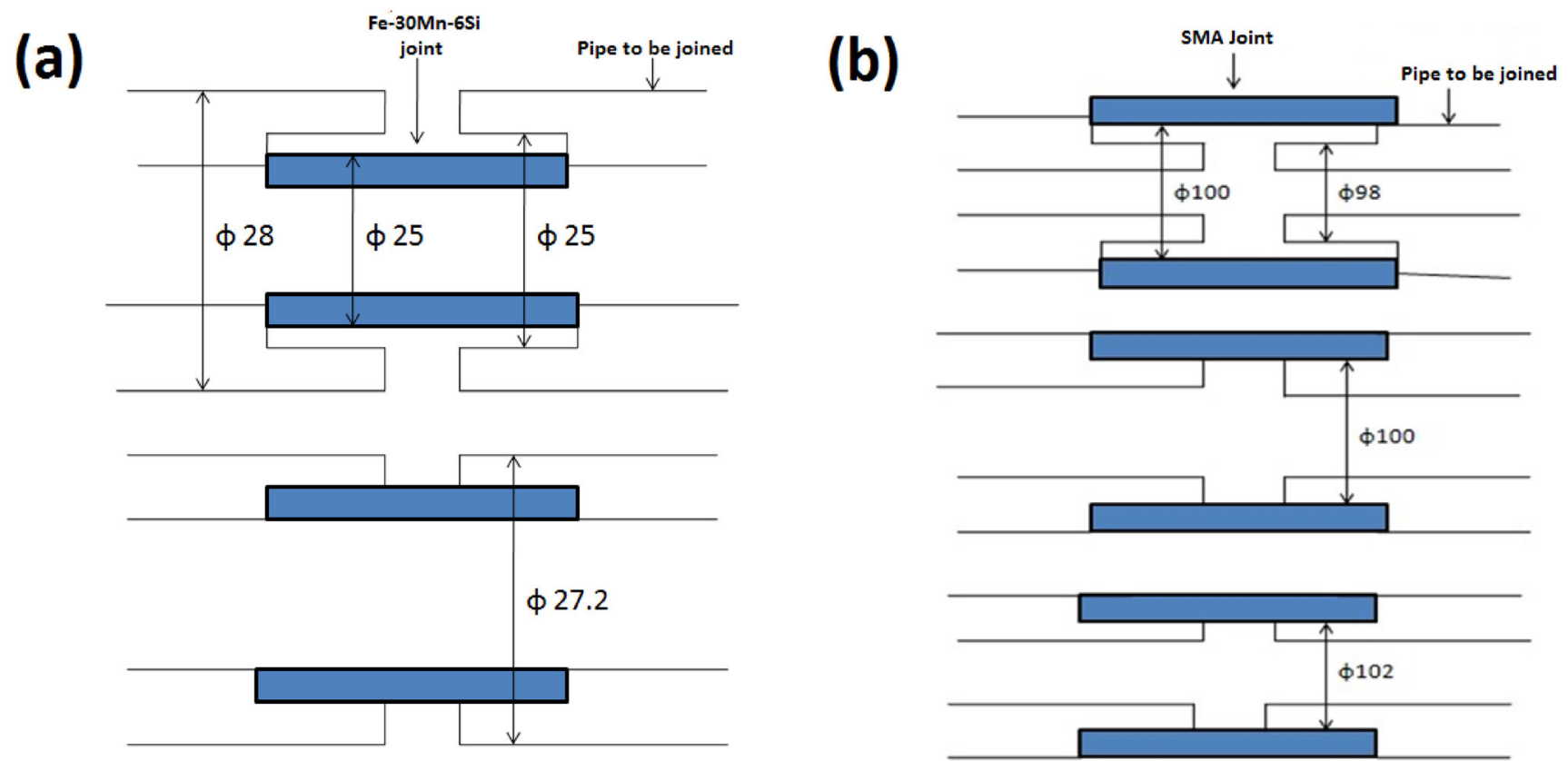

Fig. 4 Installation of SMA coupling a Fe-based SMA, b NiTi-based SMA

fear that the coupling joined by this process may deform when the temperature reaches the transformation temperature. If such a situation arises, then component failure will be observed due to loosening in driving and driven shaft/ pipe. Additionally, the pipes to be joined contain surface defects especially due to manufacturing or welding operations. Sometimes, the roundness of the pipes is not perfect or the diametrical tolerance is too large which results in not too tight coupling and non-uniform stress distribution due to improper skin contact. This eventually leads to failures in the system. These problems could be solved by providing an artificial joint between the coupling and shaft/ pipe during heating. Researchers have invented a pipe coupling arrangement as shown in Fig. 5 which is comprised of a shape memory alloy cylindrical coupling

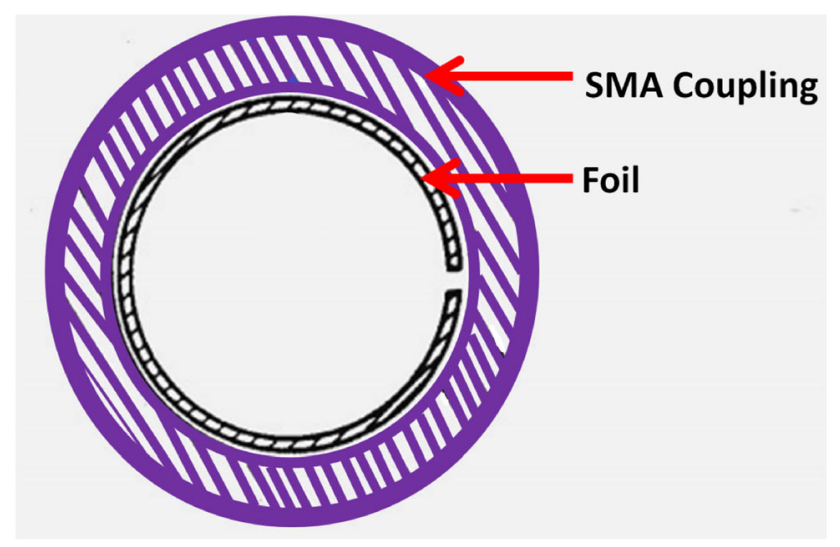

Fig. 5 Coupling agent and foil arrangement in a coupling system member and a foil of low melting point attached to the inner surface of the coupling. Upon heating above $A_{f}$, the foil gets melted between the coupler and the pipe providing an additional joint. This technique can be used in internal and external coupling methods as well (Duerig et al. 2013; Hagio et al. 1992).

Another interesting way of providing constraint between coupler and shaft is to create a locking mechanical component that could be easily installed and would provide sufficient locking force and hold the components under temperature variations as well. Justis (2001) invented a device and method which acts as a locking mechanism following stress-induced martensitic change rather than temperature-induced. Mechanical restraint is used initially to deform the SMA to the desired dimension after removal of which the SMA regains its original shape. There is no involvement of temperature whatsoever, and this technique is idle for application where the environmental temperature is above the transformation temperature of the alloy. Stress-induced martensite transformation offers higher control over the other and reduces mating part tolerance requirements.

\section{Underwater coupling concept}

Nonetheless, it is generally observed that upon continuous exposure to saline and corrosive media such as grease and chemicals, NiTi coupling could, however, develop surface degeneration which is undesirable for such a costly material. Damage of SMA was observed particularly through 
galvanic corrosion due to existing high-temperature water inside or outside of pipes. Protecting it against the harmful effect of corrosion would require the addition of alloying elements like chromium but again its shape memory effect is compromised, and it is a costly affair as well. Its remedy could be provided by shielding SMA with another material, so that SMA would not be in direct contact with corrosive agents. Mori et al. (1996a) developed a coupling that could be used in underwater pipes, as shown in Fig. 6. The pipe coupling consists of two pipes carrying water inside made of stainless steel, a tube of NiTi SMA enclosed within a cover of stainless steel having higher corrosion resistance to protect it against the risk of pitting corrosion, crevis corrosion, stress corrosion, and hydrogen embrittlement. Upon crack propagation, the coupling loses its functionality which should be avoided. The thickness of the cover was between 0.5 and $5 \mathrm{~mm}$, which is sufficiently smaller than the thickness of the SMA coupler, so that the stainless steel tube would deform simultaneously with the deformation of the SMA tube.

\section{NiTi shaft coupling system}

Superelasticity in NiTi coupling is also induced by applying stress instead of temperature. A similar shaft coupling arrangement for torque transmission is shown in Fig. 7, which can be used also for orthopedic drilling and reaming devices (Mori et al. 1996b). The assembly consists of a shaft made of NiTi alloy for transmitting torque, a tool fitting of cutting tool configuration, a radially movable flexible collet which is an integral part of the fitting, and a compression sleeve that act as a dampener. The shaft slid inside the collet forming an interference fit between the outer diameter of the shaft and the inner diameter of the collet. This interference made the collet bend outward forming a flower-shaped finger-like configuration. Afterward, the sleeve is slid over the collet and is welded at the junction. As the shaft, collet, and sleeve are assembled, the collet is forced radially onto the shaft and stress-induced transformation is activated thereby forming a secure coupling. This superelastic reaction made the fingers come in contact with the shaft throughout the length forming surface-to-surface contact. This created frictional force enables a relative movement which is essential for transmitting torque (Loughrin et al.).

\section{Factors influencing smart coupling}

The thermally induced contact stress of smart coupling depends on several factors, among which dimension and material properties of the shaft and the coupler are of prime importance. NiTi SMA absorbs and dissipates energy which is governed by temperature change, and this thermomechanical property can be manipulated by adjusting the alloy composition in the matrix. For an idle SMA coupling, the shape memory effect is best observed and preserved if temperature hysteresis is wide enough. The SMA must remain in the austenite phase during operation or motion of conduit to avoid possible re-conversion of austenite to martensite, thereby causing re-expansion, which would directly lead to loosening of residual compressive forces (Uchida et al. 2008). In order to safeguard the situation, the $\mathrm{M}_{\mathrm{s}}$ must be somewhat lower than the lowest temperature encountered, and $A_{f}$ must also be not high enough; otherwise, complete conversion of maximum residual stress would not be possible for the SMA coupling. In general, $M_{\mathrm{s}}$ and $A_{\mathrm{f}}$ should be kept low as possible. However, choosing SMA with very low $A_{\mathrm{f}}$ would cause premature contraction before or during installation which is needed to be taken
Fig. 6 NiTi coupling enclosed within stainless steel tubes for underwater application

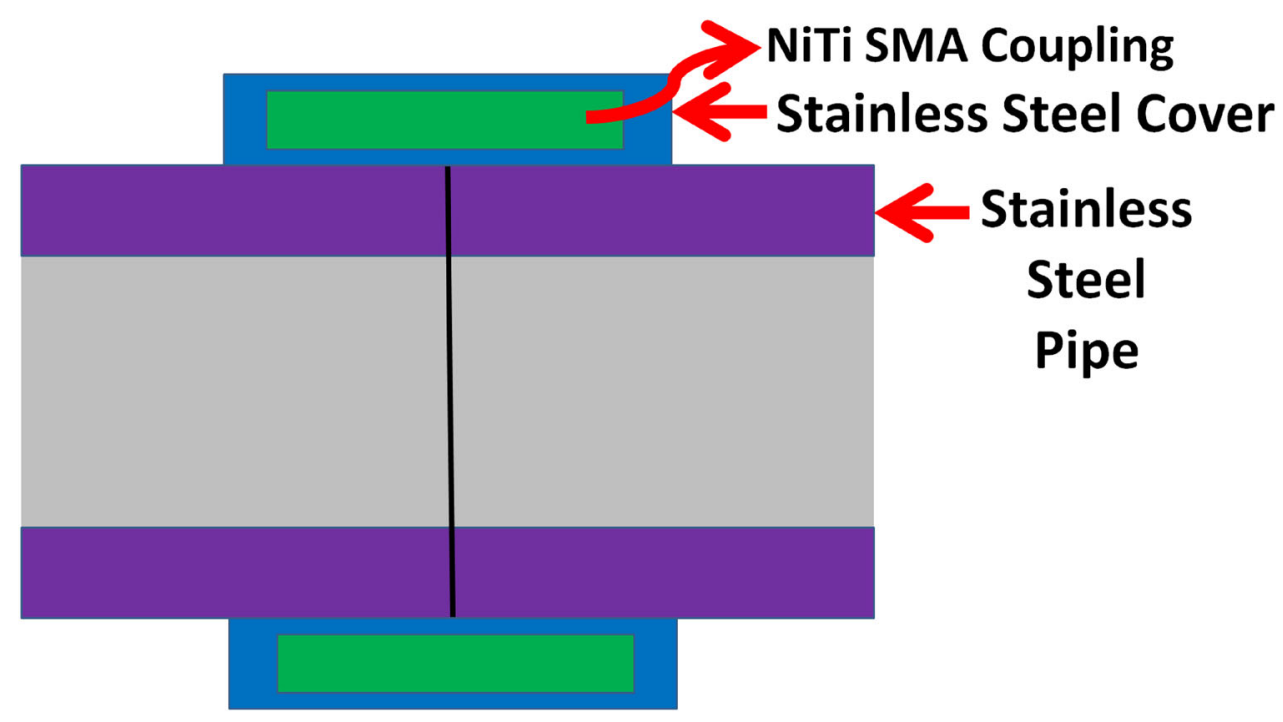


Fig. 7 Driveshaft coupling assembled system

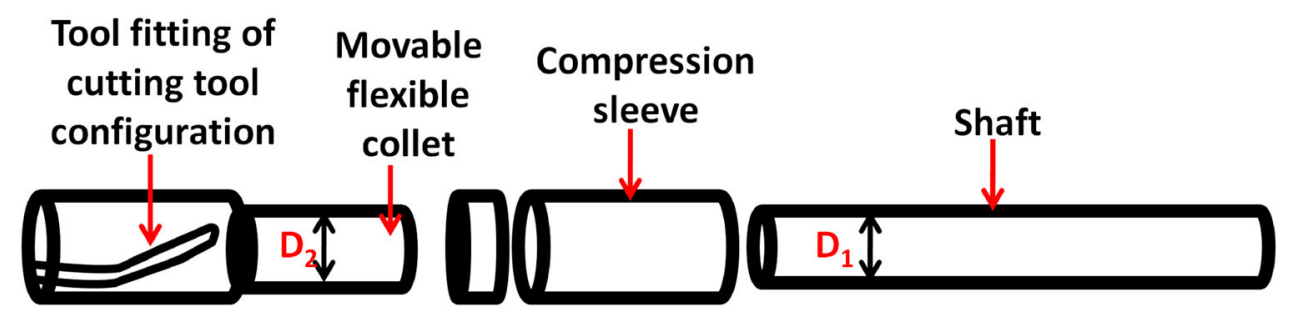

care of while selecting SMA suitable for a particular operating condition. The temperature gap between martensite transformation and austenite transformation is desired to be wider enough (Ortin and Delaey 2002). The desired property of NITINOL can be achieved by adding alloying elements, heat treatment, or a combination of both. The crystalline structure of shape memory alloys is strongly affected by heat treatment (Yan and Humbeeck 2011).

\section{Effect of the additional element}

Aluminum plays a significant role in the NiTi smart system in order to increase the ductility without affecting the shape memory effect. $\mathrm{Ni}_{2} \mathrm{Ti} \mathrm{Al}$ phase shows similar characteristics compared to $\operatorname{NiTi}\left(\beta_{2}\right)$ alloy phase. Compressive strength is seen to improve drastically at room temperature and higher temperature by substitution of Ti with Al. It was observed that an alloy with $8.4 \mathrm{~mol} \% \mathrm{Al}$ showed compressive yield strength as high as $2300 \mathrm{MPa}$ at room temperature and $200 \mathrm{MPa}$ at a temperature of around $1000{ }^{\circ} \mathrm{C}$. Although ductility was decreased in the $8.4 \% \mathrm{Al}$ alloy, a compression deformation of $5.2 \%$ is obtained. Upon further exceeding the Al content up to $11 \mathrm{~mol} \%$, $\mathrm{Ni}_{2} \mathrm{Ti}$ Al phase gets deposited as a dendrite, reducing the strength. The $\beta_{2}$ single phase $4.4 \% \mathrm{Al}$ alloy is stronger or equivalent compared with $\mathrm{NiTi}$ and Ni-base superalloy. Heat treatment through solution and aging is proven effective at $800{ }^{\circ} \mathrm{C}$, carried out for a shorter time in $7.1 \mathrm{~mol} \% \mathrm{Al}$ and $8.4 \mathrm{~mol} \% \mathrm{Al}$ at $\left(\beta_{2}+\beta^{\prime}\right)$ two-phase region (Koizumi et al. 1997). The addition of $\mathrm{Cu}$ to $\mathrm{NiTi}$ alloys reduces the transformation temperature hysteresis. Hence, they are suited for actuators, heat engine nozzle, and similar machines, but they are not idle to be used as couplers. However, the addition of $\mathrm{Nb}$ does the opposite, the transformation hysteresis gets widened, which is desired for a shape memory coupler. Most of the intermetallic phases dissolve into the B2 matrix with the solid solution treatment of NiTi parts. A microstructure consisting of a B2 matrix and nanoscale precipitation of $\mathrm{Ni}_{4} \mathrm{Ti}_{3}$ is achieved upon quenching the sample. The presence of the precipitate improves the strength of the material. The addition of $\mathrm{Nb}$ enhances the morphology of the precipitates leading to superior properties in the alloy while eliminating the R-phase in the martensitic transformation (Zhang et al. 2018).

The TiNiNbSMA has a high transformation temperature hysteresis and has thus been used in pipe joints and similar applications. Uchida et al. (2007) manufactured the alloy in a high-frequency induction vacuum furnace and prepared two samples: One sample with $\mathrm{Ni} / \mathrm{Ti}$ atomic ratio equal to 1 , and $\mathrm{Nb}$ concentration between 0 and $15 \mathrm{~mol} \%$, whereas another sample contains $\mathrm{Nb}$ concentration $6 \mathrm{~mol} \%$, and the $\mathrm{Ni} / \mathrm{Ti}$ ratio was changed from 1.025 to 1.1 . Transformation temperature decreased with increasing $\mathrm{Nb}$ content in the first sample, and a huge deviation was recorded with $\mathrm{Nb}$ being $12 \mathrm{~mol} \%$, the second sample having $\mathrm{Ni} / \mathrm{Ti}$ ratio is 1.088. The transformation temperature decreased by performing heat treatment at $673 \mathrm{~K}$ and $773 \mathrm{~K}$. This alloy is found to be more effective. Commercial Ni46.4Ti45.0Nb8.5 SMA rings were analyzed for applications as beam pipe coupling devices in radioactive places. A shape memory capacity of around $6 \%$ was observed by heating and cooling at $200{ }^{\circ} \mathrm{C}$ and $25^{\circ} \mathrm{C}$, respectively. Repeated mounting and dismounting were made possible due to the two-way SMA property (Niccoli et al. 2017). Earlier, it was believed that $\beta$-Nb particles in NiTiNb alloy produced wide hysteresis (Duerig et al. 1990), but later, it was observed that low $\mathrm{Nb}$ content upon pre-deformation could achieve significant transformation hysteresis due to changed kinetics of martensitic transformation, thereby stabilizing it. The $\mathrm{Ni}_{49.6} \mathrm{Ti}_{45.9} \mathrm{Nb}_{4.5}$ alloy exhibited similar characteristics compared to $\mathrm{Ni}_{47} \mathrm{Ti}_{44} \mathrm{Nb}_{9}$ alloy (Wang et al. 2012). Substituting Fe with Ti concentration significantly reduces the cost, and the SMA is found to exhibit good shape memory characteristics. $\mathrm{Fe}-15 \mathrm{Mn}-5 \mathrm{Si}-9 \mathrm{Cr}-5 \mathrm{Ni}$ showed $83 \%$ shape recovery for a $3.6 \%$ diameter expansion and $95 \%$ recovery for a $3 \%$ deformation which is acceptable for industrial applications. This alloy is produced by sand molding followed by annealing at $800{ }^{\circ} \mathrm{C}$. The structure possessed a high density of stacking faults and high-strength austenite. The Young's modulus of the alloy is $123.6 \mathrm{GPa}$, and after yield, the hardening rate decreases continuously. The maximum stress of $880 \mathrm{MPa}$ is attained after a total elongation of about $16 \%$ and brittle fracture can be observed (Drukera et al. 2014). $M_{\mathrm{s}}$ and $A_{\mathrm{f}}$ decrease with increased $\mathrm{Cr}$ concentration. The ternary addition of $\mathrm{Cr}$ affects martensite transformation temperatures, $M_{\mathrm{s}}$, as well 
as mechanical properties of off-stoichiometric NiTi alloys. $M_{\mathrm{s}}$ and $A_{\mathrm{s}}$ decrease with decreasing Ti concentration and change slightly when $\mathrm{Ti}$ concentration exceeds 52 at.\%, where the alloys are in the two-phase region. Significantly, $\mathrm{Ms}$ and As decreased with increasing $\mathrm{Cr}$ content at a constant $\mathrm{Ti}$ concentration. It was suggested that $\mathrm{Cr}$ atoms will substitute Ni sites preferably if only $M_{\mathrm{s}}$ changes are observed. Based on the characteristic stress-strain curves presented, the stress-induced martensitic transformation (SIMT) occurs at $196 \mathrm{C}$ (Hosoda et al. 1998). $\mathrm{Zr}$ is added to the NiTi system in an attempt to improve the corrosion resistance. When the amount of $\mathrm{Zr}$ is increased, it led to an increase in the oxidation rate. However, the corrosion rate decreases with the addition of $\mathrm{Zr}$. The reduction in the corrosion rate is attributed to the presence of oxide films. Additionally, when the content of $\mathrm{Zr}$ is below $10 \%$, the martensitic transformation temperature decreases and leads to a rapid rise in the transformation temperature when the content is more than $10 \%$. With the presence of multiple phases due to the addition of the alloying element, there is a reduction in the maximum shape recovery (Khan et al. 2017).

\section{Smart materials in automobile applications}

The use of NiTi SMA in the automobile industry is noted significantly in sports cars where performance is the prime objective. Many automotive manufactures are actively implementing this technology to simplify and improve driver control.

\section{SMA leaf spring}

Leaf springs are heavy-duty slender arc-shaped suspension system which are stacked in descending order of their sizes and bolted together. They are designed to deflect under the action of tensile or compressive load enabling them to bear high stresses and shocks. They are conventionally made of steel but sometimes due to excessive shock load, it gets permanently deformed or loosen and eventually get damaged. In order to achieve its previous dimensions and properties, using an SMA is quite beneficial in which due to temperature-induced change, it can be brought back to its original state. Integrated composite materials with NiTi SMA are successfully applied as leaf spring in heavy vehicles (Amar et al. 2016).

\section{SMA actuators and valves}

SMA is extensively used as actuators and valves in various sectors. It is truly a design miracle where a single SMA wire can replace a complex mechanical system used for actuation. The effect can be created by temperature-induced shape change either due to the application of heat or electric current. An interesting application is a temperature-controlled governer valve that controls shifting in an automatic transmission system. As shown in Fig. 8, at one end, there is a spring coil made of steel, and at the other end, there is an SMA spring coil. At low temperature, the SMA coil is in the martensitic state which have lower strength than that of steel, as a result, the spring force of the steel overcomes that of SMA. The valve is now closed as the movable piston is moved by the steel spring. When the temperature of the transmission system increases and reaches the transformation temperature of austenite, SMA strengthens and imparts greater force than steel thereby pushing the piston in the reverse direction which opens the valve. This ensures smooth operations at low temperatures, controls fuel consumption, and improves cold starting (Dieter 2013).

This technology is identified in the automatic transmission system of Mercedes Benz for smooth gear shifting (Stöckel 1995). These pneumatic valves were mass-produced by AlfmeierPräzision and were successfully implemented in car seats for providing lumbar support to the driver. Observing the benefits of this technology, many automobile manufacturers nowadays are installing SMA device such as Porsche, Hyundai, Ford Motors, and Volkswagen (Jani et al. 2014). Another similar application of the SMA actuator is observed in the general motor's Chevrolet Corvette where the actuation is electrically controlled to open and close the trunk more easily. In the previous models, the trapped air inside the vent makes the lid difficult to function. In this mechanism, the SMA wire contracts once activated, moving a lever arm to open the vent and thereby closing the trunk lid. When the trunk lid is closed, the electrical current is turned off, providing enough time for the wire to cool down and regain its original shape, closing the vent and keeping the cabin at a comfortable temperature (G. M. 2013). In the automobile industry, different types of couplings have been implemented in different sectors according to their design consideration, material behavior, and load orientations (axial, transverse). It is very crucial to select and design a coupling for a particular operation. The following Table 3 describes different couplings used for various applications by their designing parameters. Complexity in geometry is observed with greater load-carrying capacity; for lighter load, rigid coupling such as a sleeve or split muff is used. For heavy-duty applications, gear or flange couplings are used as complex parts. 


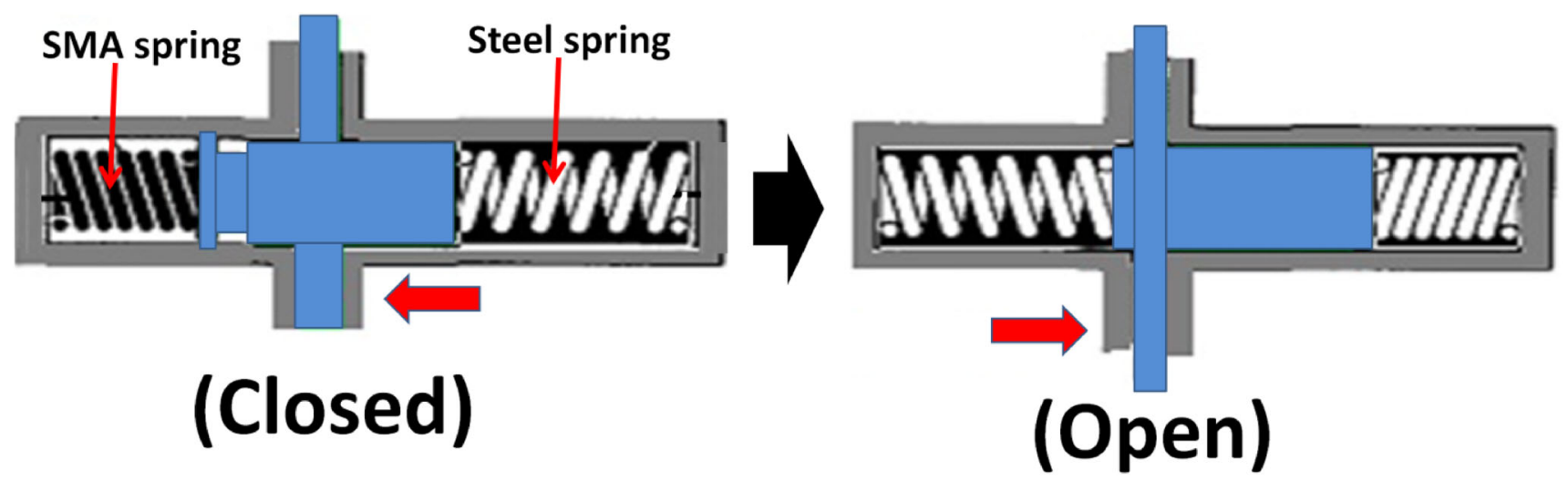

Fig. 8 SMA actuator conifguration (Singh et al. 2018)

Table 3 Installation of coupling (Bush 1936; Bhattacharjee et al. 2020; Wang et al. 2018; Sawalhi et al. 2019; Ahmed et al. 2014; DaSilva et al. 2008; Medrea et al. 2013; Valentini 2014; Vesali et al. 2012)

\begin{tabular}{|c|c|c|}
\hline Type & Design consideration & Application \\
\hline $\begin{array}{l}\text { Muff or sleeve } \\
\text { coupling }\end{array}$ & Load capacity is light to medium duty & Power transmission in shafts, joints \\
\hline Split muff coupling & Medium to heavy load with moderate speed & Line shaft in power transmission \\
\hline Flange coupling & Medium to heavy-duty industrial application & Connect the electric motor to the pump or compressor \\
\hline $\begin{array}{l}\text { Bush pin type flexible } \\
\text { coupling }\end{array}$ & $\begin{array}{l}\text { Medium duty applications permitting little angular, parallel } \\
\text { or axial misalignments }\end{array}$ & Electric motors and machines \\
\hline Gear coupling & $\begin{array}{l}\text { Heavy-duty application where the requirement of torque } \\
\text { transmission is high }\end{array}$ & Power transmission in cars \\
\hline Fluid coupling & $\begin{array}{l}\text { Marine and industrial application } \\
\text { Can provide controlled power transmission }\end{array}$ & Semi-automatic and automatic transmission \\
\hline Oldhams coupling & Used where lateral misalignments are there & Robotics, printers \\
\hline Rzeppa joint & Used in vehicles with independent rear suspension & Wheels of rickshaws \\
\hline Universal joint & $\begin{array}{l}\text { Accommodate angular misalignments } \\
\text { Used where space restriction is there }\end{array}$ & $\begin{array}{l}\text { Power transmission through propeller shafts (trucks), } \\
\text { Aircrafts, driveshaft }\end{array}$ \\
\hline
\end{tabular}

\section{Universal coupling drive shaft concept}

A universal joint, also known as a universal coupling (Fig. 9), a U-joint, a Cardan joint, a Hardy-Spicer joint, or a Hookes joint, is a joint or coupling in a rigid rod that causes the rod to "bend" in any direction. It is widely used in shafts that convey rotary motion permitting angular misalignment. Universal joints (or U-joints) are located at both ends of the driveshaft in rear-wheel-drive trucks. U-joints are connected to yokes, which allow drive shafts to move fore and aft as cars travel over bumps and dips in the road, effectively shortening or lengthening the shaft. When these constant velocity joints in front-drive cars wear out, they also make a clicking noise. Protective rubber boots are used to cover CV joints, and if the boots crack or are otherwise damaged, the joints will lose their lubrication and become damaged by dirt and moisture (Bayrakceken et al. 2007). The Cardan joint has one major flaw: The output drive shaft rotates at a variable speed, causing vibration and wear even when the input drive shaft rotates at a constant speed. A damaged Cardan joint also causes severe vibrations in the output shaft. Such vibrations can severely harm other components of the power transmission mechanisms (Vesali et al. 2012). However, with NiTi smart center block use, vibration mitigation can be successfully carried out with prolonged life expectancy and no external protective covering will be needed. Also, the center block can accommodate excessive misalignment and vibrations when the vehicle is subjected to base excitations on the road or uneven power generation from the engine under variable load conditions. The improved torsional ability and high strength of this SMA universal coupling over steel (material) enable the user with smoother driving and safety. 
Fig. 9 NiTi smart universal joint (http://img.style-js.com/a. asp $x$ ?cid $=40 \&$ cname $=$ cross+type+universal+joint)

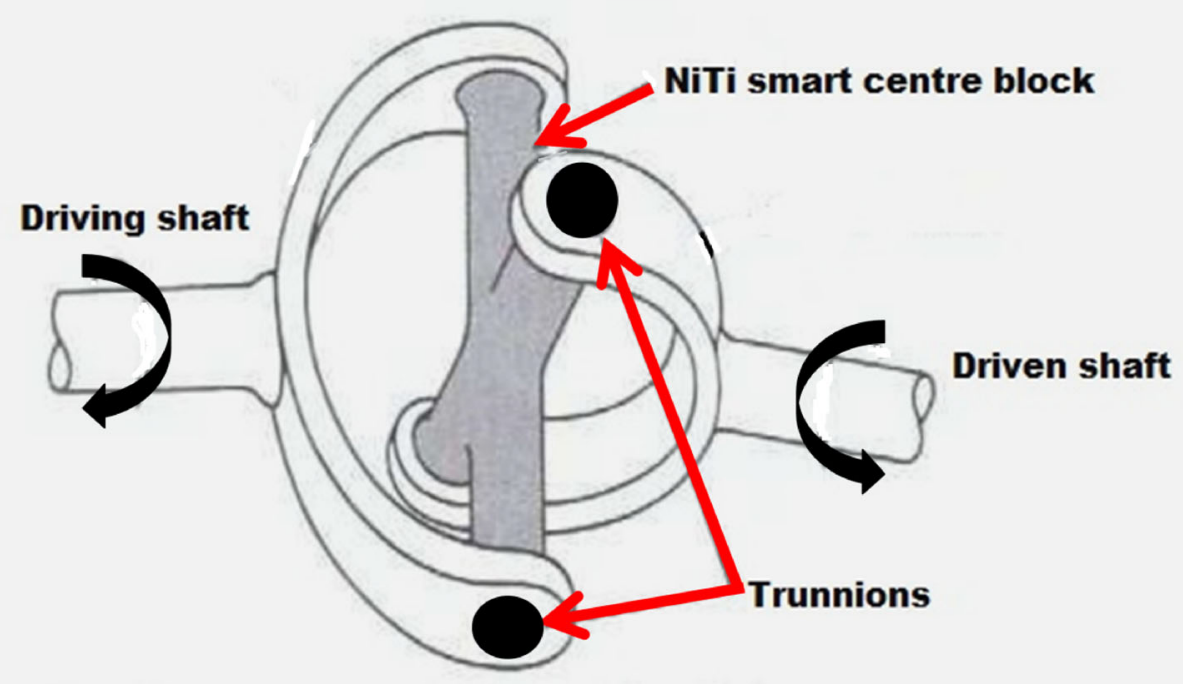

coordination supports motion (Shina et al. 2018). The balls used in the Rzeppa joint are susceptible to corrosion, rapid pitting in the races leading to early failure of the system. Corrosion-proof bearings offer low strength and fail prematurely due to accelerated wear and fatigue during operation. However, balls made of NiTi provide resistance against corrosion in most of the corrosive agents. These SMA balls are designed and tested successfully in a ballbearing arrangement. Its improved mechanical properties against fatigue and its higher strength as compared to steel
Fig. 10 NiTi ball elements in Rzeppa joint (https://

slideplayer.com/slide/3867278/)

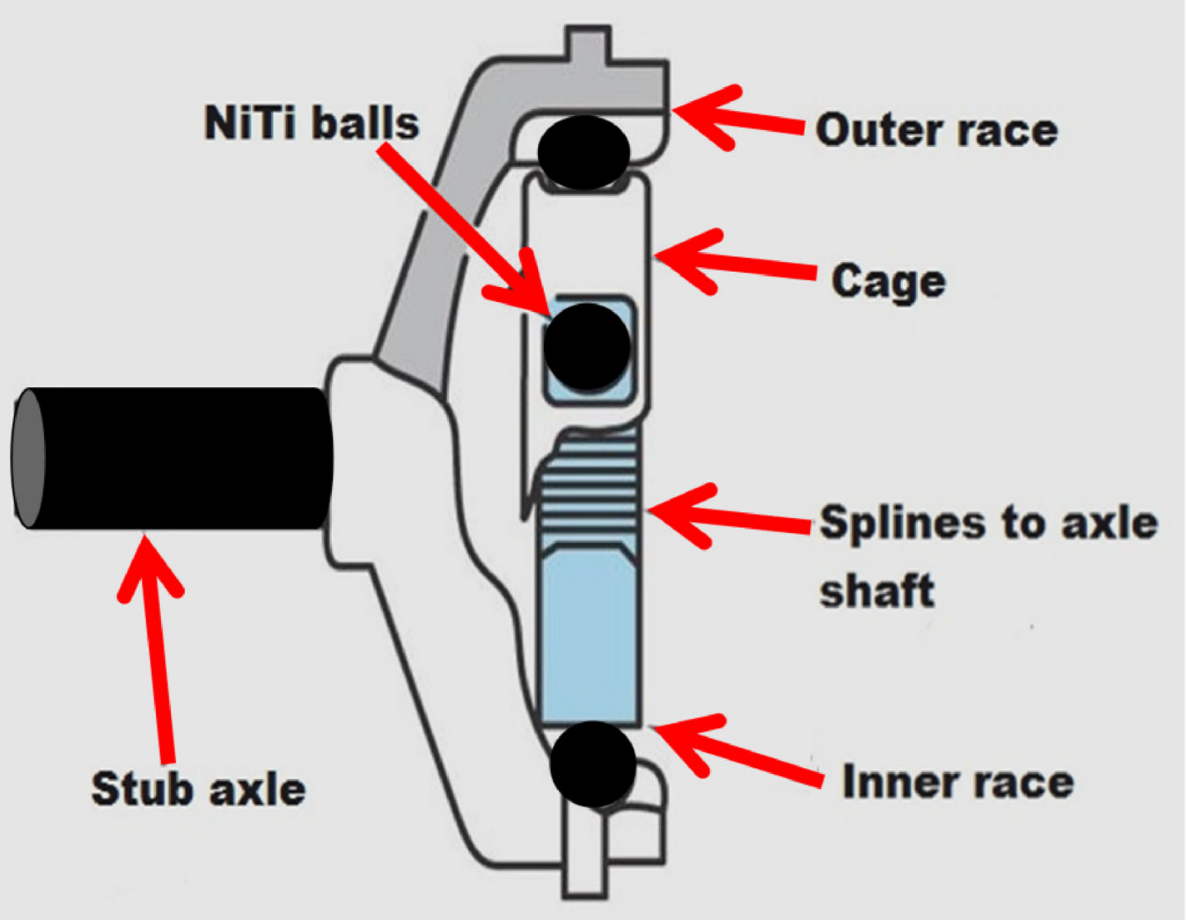


SMA-assisted part do not fluctuate even at elevated temperatures, making it a better alternative than conventional ones (Gerald 2005). This study suggested that these balls can be used in the Rzeppa joint on account of which they can adjust themselves for angular misalignment to protect the coupling against high amplitude vibrations, providing stable working.

\section{Gear coupling concept}

A gear coupling is the first choice of many companies to swap movements from one component to the next, regardless of industry type or size. This mechanical component allows us to pair two drive components while also transmitting power perfectly (Fig. 11). Even with nearperfect alignment, gear couplings can produce significant static forces and moments that can affect turbomachinery vibrations. This theory has been confirmed through various testing and case studies. These forces have the potential to transform bearing loads, stiffness, and damping, resulting in high vibration (Palazzolo et al. 1992). Installing gear assembly made of NiTi SMA can suppress excessive vibrations, prevent interference, backlash, fatigue failure over a wide range of temperatures. Aiding to its vibration damping properties, the gear made of NiTi maintains contact by decreasing the amount of backlash without tooth failure and is capable of withstanding heavy friction (Kacalak et al. 2018).

\section{Advantages and limitation of NiTi coupling}

NITINOL has many advantages over steel as coupling material in different sectors like aerospace, shipbuilding, hydraulic lines, space satellite. Now, it is time to implement this technology in the automobile industry because of its superelasticity, torsional strength, and vibration damping properties. Although its initial cost is high, however, they work remarkably in the automobile sector by reducing the maintenance cost of the final product due to its technical benefits. So, it is a major challenge for the researchers to make use of this coupling technology in the automobile industry, considering consumer acceptance from the economic point of view. NITINOL SMA coupling offers many advantages, such as:

a. No expansive tooling

b. Leak-proof and permanent connection

c. Lightweight design

d. Quick and easy installation

e. Lower space is required around the pipes or shafts.

However, transportation and storage cost are considerable for NiTi SMA. NITINOL is kept below its transformation temperature which is around $-100{ }^{\circ} \mathrm{C}$ maintained inside liquid nitrogen during transportation to the manufacturing unit. Later, at this temperature, the coupling joins the shaft or pipe. This degree of sub-cooling maintained throughout the process increases the overall cost of SMA coupling (Vinothkumar et al. 2015). Storage and transportation of NITINOL are costly at cryogenic temperature, devising a proper technique to felicitate its storage at room temperature becomes a research direction of SMA. NITINOL is expensive, its application is limited to high-end applications where cost is not a factor, its production cost is a major drawback in setting it for commercial purposes, a cheaper production method could be invented, and material exhibiting similar shape memory capacity should be researched in future.
Fig. 11 Gear coupling (https:// kapent.com/what-are-couplingstypes-of-couplings-and-theirapplication/)

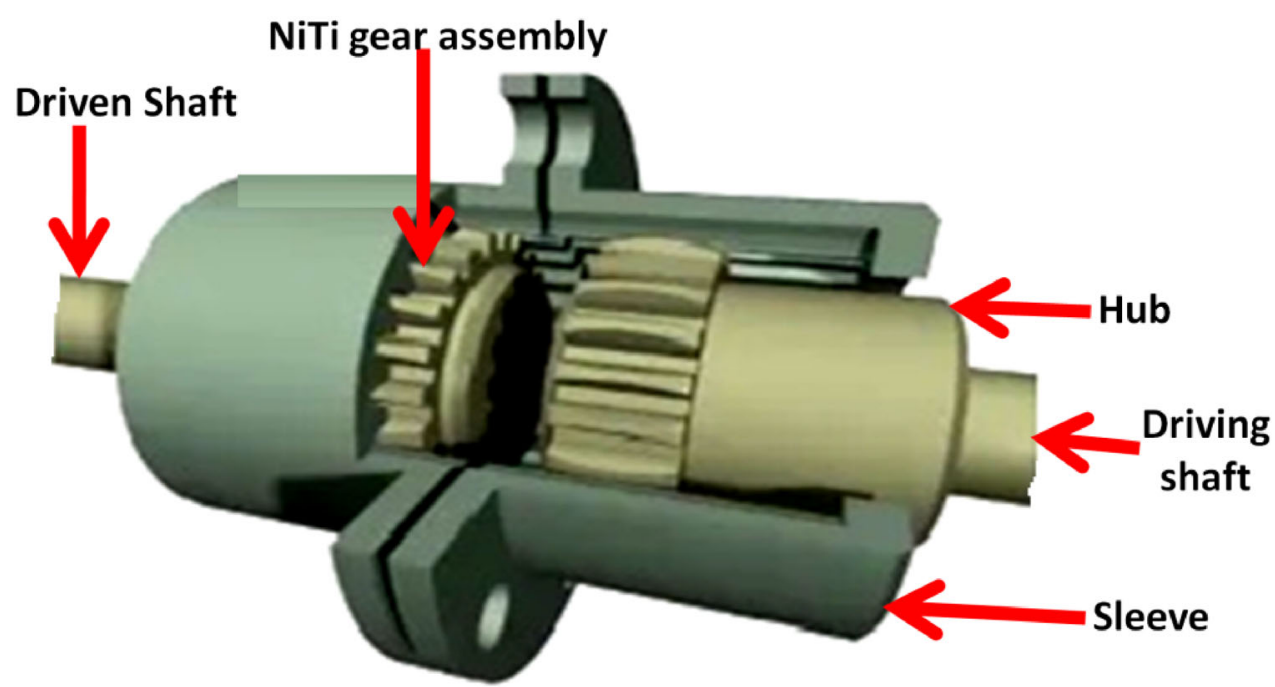




\section{Summary and future prospect}

Metal alloys with shape memory belong to a group of smart materials that can be used as a coupling agent. SMA coupling systems are an excellent example of a product that helps significantly reduce process costs in comparison with traditional assembly methods, such as welding, brazing, or swaging. The presented coupling and its examples are very much effective and reliable for connecting shafts in the transmission line of automobiles and can be implemented in place of conventional couplings. The method of installation and variable parameters are mentioned for effective joining, analogous to propeller shafts in cars. This alternative coupling is a solution for design simplicity of structure, durability, and shorter processing. If properly designed and engineered, SMA couplers provide a product that can enhance shaft fitting in various industrial applications. The design characteristics of small mass and single-motion actuation of the SMA interference coupling should allow for a wide range of latch and fastener applications. Alternatively, the scale of the SMA interference coupling need not be limited to small sizes but could be scaled up in size and strength to meet other types of coupling needs. Featuring simplicity, strength, and reliability, the SMA interference coupling proved a useful component in the automobile industry.

Open Access This article is licensed under a Creative Commons Attribution 4.0 International License, which permits use, sharing, adaptation, distribution and reproduction in any medium or format, as long as you give appropriate credit to the original author(s) and the source, provide a link to the Creative Commons licence, and indicate if changes were made. The images or other third party material in this article are included in the article's Creative Commons licence, unless indicated otherwise in a credit line to the material. If material is not included in the article's Creative Commons licence and your intended use is not permitted by statutory regulation or exceeds the permitted use, you will need to obtain permission directly from the copyright holder. To view a copy of this licence, visit http://creativecommons. org/licenses/by/4.0/.

\section{References}

Ahmed S, Goh C, Allen JK, Mistree F, Zagade P, Gautham BP (2014) Hot forging of automobile steel gear blanks: an exploration of the solution space. In: Proceedings of the ASME 2014 international design engineering technical conferences and computers and information in engineering conference. Volume 2B: 40th design automation conference. Buffalo, New York, USA, pp 17-20, V02BT03A003. ASME. https://doi.org/10.1115/ DETC2014-34197

Amar Y, Chinmay M, Shridhan P (2016) Use of smart material made an industrial revolution in development of automobile. J Comput Eng. e-ISSN: 2278-0661, p-ISSN: 2278-8727, 09-12

Bayrakceken H, Tasgetiren S, Yavuz I (2007) Two cases of failure in the power transmission system on vehicles: a universal joint yoke and a drive shaft. Eng Fail Anal 14:716-724
Bhandari VB (2001) Introduction to machine design, 1st edn. McGraw Hill, New Delhi

Bhattacharjee P, Dey V, Mandal UK (2020) Risk assessment by failure mode and effects analysis (FMEA) using an interval number based logistic regression model. Saf Sci 132:104967

Broyles HC, Jervis JE (1973) Heatrecoverable metallc coupling. Patent no US4035007A

Bush HD (1936) Compression-ignition engines for rail traction. Proc Inst Automob Eng 30(2):558-576

Chen X, Chen B, Peng X, Jin X, Ma Y, Zhao Y, Zheng H (2020) Finite element simulation of NiTiNb shape memory alloy pipejoint subjected to coupled transformation and plastic deformation. Adv Mater Sci Eng 2020, Article ID 6895850

Crane WM, James HN, Marcello R (2014) Characterization of a shape memory alloy interference coupling. Smart Mater Struct 23(11): 115011

Cuia G, Zhenxiao B (2020) A comprehensive review on smart anticorrosive coatings. Prog Org Coat 148(105821):1-26

DaSilva MJ, Lu Y, Sühnel T, Schleicher E, Thiele S, Kernchen R, Diele K-H, Hampel U (2008) Autonomous planar conductivity array sensor for fast liquid distribution imaging in a fluid coupling. Sens Actuators A 147(2):508-515

Deepam G, Pabla BS (2015) Condition based maintenance of machine tools: a review. CIRP J Manuf Sci Technol 10:24-35

Dieter S (2013) Engineering aspects of shape memory alloys, 1st edn. Butterworth-Heinemann, Oxford, p 512

Drukera AV, Perotti A, Esquivel I, Malarría J (2014) A manufacturing process for shaft and pipe couplings of $\mathrm{FeMnSiNiCr}$ shape memory alloys. Mater Design 56(C):878-888

Du Q, Xu H (2015) Shape memory alloy in various aviation field. Procedia Eng 99:1241-1246

Duerig TW, Melton K, Proft JL, Duerig TW (1990) Engineering aspects of shape memory alloys, 1st edn. Butterworth-Heinemann, London, p 512

Duerig TW, Melton KN, Stöckel D (2013) Engineering aspects of shape memory alloys, 2nd edn. ISBN: 9781483144757, p 512

G. M. Chevrolet Debuts Lightweight 'Smart Material' on Corvette. General Motors News; 2013. https://media.gm.com/media/us/en/ $\mathrm{gm} /$ home.detail.html/content/Pages/news/us/en/2013/Feb/0212corvette.html\#: :text=In\%20addition $\% 2 \mathrm{C} \% 20$ the $\% 20$ rede signed $\% 20$ seventh,releases $\% 20$ air $\% 20$ from $\% 20$ the $\% 20$ trunk

George BK, Isaac M (1997) The story of nitinol: the serendipitous discovery of the memory metal and its applications. Chem Educ $2: 1-21$

Gerald JJ (2005) NITINOL ball bearing element and process for making. Patent no AU6786800A

Hagio A, Ono Y, Honma H (1992) Pipe coupling using shape memory alloy with inner solder foil member. Patent number: US5150931A

Hosoda H, Hanada S, Inoue K, Fukui T, Mishimad Y, Suzuki T (1998) Martensite transformation temperatures and mechanical properties of ternary NiTi alloys with offstoichiometric compositions. Intermetallics 6:291-301

http://img.style-js.com/a.aspx ?cid=40\&cname $=$ cross + type + univers al+joint

https://kapent.com/what-are-couplings-types-of-couplings-and-theirapplication/

https://slideplayer.com/slide/3867278/

Jani JM, Leary M, Subic A (2014) Shape memory alloys in automotive applications. Appl Mech Mater 663:248-253

Jee KK, Han JH, JungW S, Jang WY (2006) Suggestion of pipe coupling method for maximum and uniform joining stress. Mater Trans 47(3):750-752

Juergen B (1983) Torquing of stainless steel and Nitinol wires A comparison of mechanical properties. Eur J Orthod 5:167-169 
Justis JR (2001) Device and method for selectively preventing the locking of a shape memory alloy coupling system. Patent no: US6273888B1

Kacalak W, Majewski M, Budniak Z (2018) Innovative design of non-backlash worm gear drives. Arch Civ Mech Eng 18(3):983-999. https://doi.org/10.1016/j.acme.2018.01.011

Kai Z, Sirong Y (2020) Preparation of wear and corrosion resistant micro-arc oxidation coating on 7N01 aluminum alloy. Surf Coat Technol 388(125453):1-10

Karakoc O, Yegin Y, Ozdogan M, Salman M, Nagabandi N, Yegin C, Yurukcu M, Sari MM (2021) Chapter one: smart and state-ofthe-art materials in oil and gas industry. In: Sustainable materials for transitional and alternative energy, Volume $\mathbf{2}$ in advanced materials and sensors for the oil and gas industry, pp 1-51

Khan SMB (2019) Master of Science in Mechanical Engineering, Effect of Unbalance Forces on Ball Bearing Surface Defect, Department of Mechanical Engineering, Dhaka University of Engineering \& Technology, Gazipur, Bangladesh. https://www. duet.ac.bd/wp-content/uploads/2020/09/Thesis_5203085P.pdf

Khan AN, Mohsin M, Abdul W (2017) Development and characterization of Nickel-Titanium-Zirconium shape memory alloy for engineering applications. Russ J Non-Ferr Met 58(5):509-515

Koizumi Y, Ro Y, Nakazawa S, Harada H (1997) NiTi-base intermetallic alloys strengthened by A1 substitution. Mater Sci Eng A 223:36-41

Liu DZ, Wang DF, Ji WY, Liu WX (2006) Suggestion of pipe coupling method for maximum and uniform joining stress. In: Proceedings 2nd international conference on SMST, vol 47, 3, pp 329-334

Loughrin T, Zubik J, Schott W. Drive shaft coupling. Patent no: US7314416B2

Manoj SR, Prakash M, Nirmal R, Gaurav V (2020) Vibration analysis of nitinol shape memory alloy in carbon fibre reinforced polymer composites. IOP Conf Ser Mater Sci Eng 912:052029

Medrea C, Sideris J, Chicinaş I, Ventouris S (2013) Analysis of fracture and cracks of oldham's, couplings used in anchor hoisting. Case study. Eng Fail Anal 35:590-596

Mehmet K, Ömer Ç, Behçet G (2017) Thermomechanical cyclic stability of porous NiTi shape memory alloy. Mater Res Bull 95:243-247

Mori T, Kondo Y, Satoh H, Hattri S, Kato T, Yanai Y (1996a) Shape memory alloy pipe coupling and underwater pipes. Patent number: EP0632224A2

Mori T, Kondo Y, Satoh H, Hattri S, Kato T, Yanai Y (1996b) Shape memory alloy pipe coupling for underwater pipes. Patent no: EP0632224B1

Mori T, Kondo Y, Satoh H, Hattri S, Kato T, Yanai Y (1997) Shape memory alloy pipe coupling and underwater pipes. Patent number: 5687995

Naresh C, Bose PSC, Rao CSP (2016) Shape memory alloys: a state of art review. IOP Conf Ser Mater Sci Eng 149:012054

Niccoli F, Garion C, Maletta C, Sgambitterra E, Furgiuele F, Chiggiato P (2017) Beam-pipe coupling in particle accelerators by shape memory alloy rings. Mater Des 114:603-611

Niccolia F, Garion C, Malettaa C, Sgambitterra E, Furgiuele F, Chiggiato P (2017) Beam-pipe coupling in particle accelerators by shape memory alloy rings. Mater Des 114:603-611

Nnamchi P, Younes A, González S (2019) A review on shape memory metallic alloys and their critical stress for twinning. Intermetallics 105:61-78

Ortin J, Delaey L (2002) Hysteresis in shape-memory alloys. Int J Non-Linear Mech 37:1275-1281

Otsuka K, Ren X (2005) Physical metallurgy of Ti-Ni-based shape memory alloys. Prog Mater Sci 50:511-678

Palazzolo AB, Locke SR, Calistrat M, Clark RW, Ayoub A, Calistrat D, Tang P (1992) Gear coupling misalignment induced forces and their effects on machinery vibration. Texas A\&M University. Turbomachinery Laboratories, pp 83-96. https://hdl.handle. net/1969.1/163525

Pamela JK (1987) Heat recoverable coupling use in naval shipboard piping systems. SAE Trans 96(3):391-395

Patil D, Song G (2016) Shape memory alloy actuated accumulator for ultra-deepwater oil and gas exploration. Smart Mater Struct 25:045012

Raphael SS, Thiago GR (2021) Shape memory alloy couplers applied for torsional vibration attenuation of drill-string systems. J Petrol Sci Eng 202(108546):1-12

Sawalhi N, Ganeriwala S, Tóth M (2019) Parallel misalignment modeling and coupling bending stiffness measurement of a rotorbearing system. Appl Acoust 144:124-141

Sharma N, Jangra KK, Raj K (2015) Fabrication of NiTi alloy: a review. Proc Inst Mech Eng Part L J Mater Des Appl 232(3):250-269

Shina JK, Choi SR, Ahn SJ, Kim DW (2018) Contact ratio analysis of the Rzeppa joint based on full-static modeling. Mech Mach Theory 119(4):236-251

Singh A, Singh JR, Verma PK (2018) Automotive application of shape memory alloys. In: 15 th international conference on recent trends in engineering. Applied science and management. ISBN: 978-93-87793-18-7

Stephen RL, Joseph PC, Michael JB, Thomas DH (2013) Coupling credible failure modes and owner options to intervene. In: Proceedings of the forty-second turbomachinery symposium, September 30-October 3, 2013, Houston, Texas. https://core.ac. uk/download/pdf/87264507.pdf

Stöckel D (1995) The shape memory effect: phenomenon, alloys, applications. In: Shape memory alloys for power systems (EPRI), pp 1-13

Tabesh M, Atli KC, Rohmer J, Franco BE, Karaman I, Boyd JG, Lagoudas DC (2012) Design of shape memory alloy pipe couplers: modeling and experiments. Conf Pap Proc SPIE Int Soc Opt Eng. https://doi.org/10.1117/12.915361

Tabesh M, Boyd J, Atli KC (2017) Design, fabrication, and testing of a multiple-actuation shape memory alloy pipe coupler. J Intell Mater Syst Struct 29(6):1165-1182

Tabesh M, Boyd J, Atli KC, Karaman I, Lagoudas D (2018) Design, fabrication, and testing of a multiple-actuation shape memory alloy pipe coupler. J Intell Mater Syst Struct 29(6):1165-1182

Uchida K, Shigenaka N, Sakuma T, Sutou Y, Yamauchi K (2007) Effect of $\mathrm{Nb}$ content on martensitic transformation temperatures and mechanical properties of Ti-Ni-Nb shape memory alloys for pipe joint applications. Mater Trans 48(3):445-450

Uchida K, Shigenaka N, Sakuma T, Sutou Y, Yamauchi K (2008) Effects of pre-strain and heat treatment temperature on phase transformation temperature and shape recovery stress of $\mathrm{Ti}-\mathrm{Ni}-$ $\mathrm{Nb}$ shape memory alloys for pipe joint applications. Mater Trans 49(7):1650-1655

Valentini PP (2014) Effects of the dimensional and geometrical tolerances on the kinematic and dynamic performances of the Rzeppa ball joint. Proc Inst Mech Eng Part D J Automob Eng 228(1):37-49

Vesali F, Rezvani MA, Kashfi M (2012) Dynamics of universal joints, its failures and some propositions for practically improving its performance and life expectancy. J Mech Sci Technol 26:2439-2449

Vinothkumar TS, Kandaswamy D, Prabhakaran G, Rajadurai A (2015) Microstructure of cryogenically treated martensitic shape memory nickel-titanium alloy. J Conserv Dent 18(4):292-296

Wada K, Liu Y (2005) Shape recovery of NiTi shape memory alloy under various pre-strain and constraint conditions. Smart Mater Struct 14:S273 
Wagner ER, Cooney CE (1979) Universal joint and driveshaft design manual. Advances in Engineering Series, No. 7, Society of Automotive Engineers, Warrendale, PA. ISBN of 978-0-89883007-1, p 440

Wang M, Jiang M, Liao G, Guo S, Zhao X (2012) Martensitic transformation involved mechanical behaviors and wide hysteresis of NiTiNb shape memory alloys. Prog Nat Sci Mater Int 22(2):130-138

Wang Y, Lang L, Sherkatghanad E (2018) Rigid-flexible coupling forming process for aluminum alloy automobile body panels. Int J Adv Manuf Technol 95:3905-3918

William CM (2010) Thesis: development of a nano-satellite microcouplingmechanism with characterization of a shape memoryalloy interference joint, Monterey, California. Naval Postgraduate School. https://core.ac.uk/download/pdf/36698725.pdf
Wolfgang P, Martin K, Adam K (2006) Cyclic torsional loading of pseudoelastic NiTi shape memory alloys: damping and fatigue failure. Mater Sci Eng A 417:182-189

Yan X, Humbeeck JV (2011) Effect of annealing on strain-temperature response under constant tensile stress in cold-worked NiTi thin wire. Smart Mater Res 2011, Article ID 160927

Zhang F, Zheng L, Wang F, Zhang H (2018) Effects of Nb additions on the precipitate morphology and hardening behavior of Ni-rich Ni55Ti45 alloys. J Alloys Compd 735:2453-2461

Publisher's Note Springer Nature remains neutral with regard to jurisdictional claims in published maps and institutional affiliations. 